\title{
ESPAÇO ESCOLAR SOB A VISÃO DAS CRIANÇAS: NARRATIVAS, PERCEPÇÕES E REPRESENTAÇÕES
}

\author{
SCHOOL SPACE UNDER THE VISION OF CHILDREN: NARRATIVES, PERCEPTIONS AND \\ REPRESENTATIONS
}

\section{ESPACIO ESCOLAR BAJO LA VISIÓN DE LOS NIÑOS: NARRATIVAS, PERCEPCIONES Y REPRESENTACIONES}

\author{
Fabrício Oliveira da Silva ${ }^{1}$ \\ Michele Rodrigues Marques ${ }^{2}$
}

\begin{abstract}
Resumo: O presente trabalho discorre sobre o modo como crianças da Educação Infantil veem e atribuem sentido ao espaço escolar. As discussões teóricas permeiam fundamentações que evidenciam caracterizações do espaço escolar, defendendo que estes espaços não devem ser pensados e organizados apenas pelo professor. $O$ trabalho tem como objetivo analisar narrativas de crianças de quatro a seis anos sobre a organização dos espaços da escola que frequentam. A pesquisa foi realizada numa escola da rede municipal de uma cidade do interior baiano. $O$ estudo tem como referencial teórico e metodológico contribuições de Passegi (2011), Ferraroti (1988), Horn (2011), Ariés (1981), Freire (2005), Vygotski (2003), dentre outros. O procedimento metodológico usado foi inspirado na abordagem (auto)biográfica, em que as narrativas infantis constituíram o dispositivo principal de recolha de informações. Com esta pesquisa foi possível constatar que o espaço precisa ser desafiador para que a criança possa despertar seu interesse, proporcionando o brincar, o criar, o imaginar, contribuído para a construção de seus conhecimentos.
\end{abstract}

Palavras-chave: Educação Infantil. Narrativas infantis. Organização dos espaços.

\begin{abstract}
The present work deals with the way children from kindergarten see and attach meaning the school space. The theoretical discussions permeate foundations that show the characterization of the school space, arguing that these spaces should not be thought and organized only by the teacher. The objective of this work is to analyze children 's narratives from 04 to 06 years old about the organization of the school spaces they attend. The research was carried out in a school of the municipal network of a city in the interior of Bahia. The study has as theoretical and methodological
\end{abstract}

\footnotetext{
${ }^{1}$ Universidade Estadual de Feira de Santana - UEFS. Feira de Santana, Bahia, Brasil.

${ }^{2}$ Universidade do Estado da Bahia - UNEB. Irecê, Bahia, Brasil.
} 
reference contributions from Passegi (2011), Ferraroti (1988), Horn (2011), Ariés (1981), Freire (2005), Vygotski (2003), among others. The methodological procedure used was inspired by the (auto) biographical approach, where children's narratives were the main information gathering device. With this research it was possible to verify that the space needs to be challenging so that the child can arouse their interest, providing play, create, imagine, contributed to the construction of their knowledge.

Keywords: Early Childhood Education. Children's narratives. Organization of spaces.

Resumen: Este artículo discute la forma en que los niños en el jardín de infantes ven y atribuyen significado al espacio escolar. Las discusiones teóricas se desaollhan por los fundamentos que muestran caracterizaciones del espacio escolar, argumentando que estos espacios no deben ser pensados y organizados solo por el maestro. El trabajo tiene como objetivo analizar narraciones de niños de cuatro a seis años sobre la organización de los espacios escolares a los que asisten. La investigación se llevó a cabo en una escuela municipal en una ciudad del interior de Bahía. El estudio tiene como referencias teóricas y metodológicas contribuciones de Passegi (2011), Ferraroti (1988), Horn (2011), Ariés (1981), Freire (2005), Vygotski (2003), entre otros. El procedimiento metodológico utilizado se inspiró en el enfoque autobiográfico, en el que las narraciones de los niños fueron el principal dispositivo para recopilar información. Con esta investigación se descubrió que el espacio debe ser desafiante para que el niño pueda despertar su interés, proporcionar juegos, crear, imaginar y contribuir a la construcción de su conocimiento.

Palabras clave: Educación de la primera infancia. Narrativas infantiles. Organización de espacios.

\section{INTRODUÇÃO}

Falar sobre como as escolas de Educação Infantil são organizadas e como esses espaços interferem nas aprendizagens das crianças sempre nos trouxe algumas inquietações. Observando algumas turmas de Educação Infantil, entendemos, pela experiência lograda nos anos de atividade docente, que as atividades e brincadeiras realizadas têm um tempo e um espaço determinado e que o espaço nem sempre está organizado de forma que as crianças possam explorá-lo.

Pensar esses espaços não é papel unicamente do professor. As crianças que ali estão precisam ser ouvidas e suas opiniões levadas em consideração no momento de organização desses espaços. Assim, a partir das experiências do dia a dia, em que os espaços muitas vezes, mesmo que inconsciente, são organizados de forma a não permitir o livre acesso das crianças, desperta a vontade de ouvir as crianças para descobrir o que elas pensam sobre esses espaços.

Neste sentido, o presente trabalho emerge como uma experiência de ter ouvido as crianças a respeito da organização do espaço escolar, buscando conhecer, sob sua ótica analítica, como o espaço escolar deve ser organizado. Evidenciam-se muitos trabalhos que trazem para a discussão, 
o currículo da Educação Infantil como um elemento balizador para se pensar a organização dos espaços na escola, sobretudo das áreas de lazer. É muito comum que os adultos pensem sobre isso e que construam as determinações. No entanto, as crianças são capazes de produzir narrativas, a partir das quais elas fazem fluir uma lógica, um modo próprio de entender a escola e o espaço em que nela a criança brinca. É a partir dessa problemática, que buscamos neste trabalho conhecer a ótica de algumas crianças a respeito de: Como a organização dos espaços da escola é revelada em suas narrativas? O que dizem as crianças sobre a escola e as áreas de lazer?

Diante dessas questões iniciais, buscamos relacioná-las com uma problemática local, de uma instituição pública da rede municipal de uma cidade do interior baiano. Assim sendo, e olhando para a realidade desta escola, buscamos analisar como as crianças percebem o referido espaço e que considerações fazem a respeito disso. A ideia, portanto, foi a de perceber como a inserção das crianças numa realidade local determina modos de percepção e apreensão dessa realidade, para a qual buscamos analisar mais algumas questões, quais sejam: Como os espaços da escola são organizados? O que pensam as crianças sobre a organização desses espaços?

Ao buscarmos analisar a organização da escola como se apresenta e perceber o que a criança julga sobre isso, nos inserimos numa tarefa de revelar os sentidos e significados que elas atribuem, quando externam o que pensam sobre o assunto, gerando percepções que se fundamentam em sua realidade existencial, lúdica, de crianças, que tem seu próprio jeito de pensar e de agir sobre o mundo, ainda que esse modo pareça aos adultos estranho e pouco funcional. Nos ancoramos nas reflexões de Horn (2011), Ariés (1981), Freire (2005), Vygotski (2003) a fim e desenvolver reflexões sobre a criança, seu modo de aprender e de representar o aprendido.

Neste cenário, a referida pesquisa tem por objetivo analisar a narrativa das crianças sobre a organização dos espaços da escola que frequentam. Ainda como objetivos transversais, o estudo pretendeu analisar o sentido da organização dos espaços da instituição para as crianças; identificar as contribuiç̧̃̃es da organização dos espaços para as crianças; analisar como as crianças percebem e desejam os espaços na Educação Infantil.

O interesse por esse tema se deu pela motivação de produções de experiências logradas por um dos autores, dado a imersão no contexto da Educação infantil enquanto regente. Além dos anos de magistério, os diálogos com as crianças, suas inventividades, suas lógicas transcendentais da razão dos adultos é que nos impulsionou a dar visibilidade aos discursos das crianças em um trabalho dessa natureza, por meio do qual outros tantos professores poderão analisar suas 
realidades educacionais e perceber como as crianças são ativas e criadoras no que tange ao modo como vêm e compreendem a sua escola e a consequente organização que é feita desta.

Há ainda a motivação que se fundamenta no convívio cotidiano com outros colegas docentes, com os quais estabelecemos conversas sobre outras possibilidades de organização dos espaços de acordo com as características das crianças. A forma como essas escolas organizam seus espaços, seus materiais, a decoração, as possibilidades de interação entre as crianças, a falta de desafios corporais e cognitivos, e o mau uso dos espaços são questões que sempre chamaram nossa atenção.

Assim, o trabalho envolveu 04 crianças da Educação Infantil, com idades entre 4 e 6 anos. 0 estudo se fez, também, a partir de algumas situações de diálogos com as crianças, tanto coletivamente como de forma individual, por meio das quais cada uma foi narrando e abordando livremente a compreensão que tinham da escola e de como a mesma lhes parecia organizada. Nesta seara, focamos a nossa atenção para a inventividade delas em nos revelar como acreditam que a escola deveria ser estruturada sob seu ponto de vista.

Na seção seguinte, detalhamos os percursos metodológicos que adotamos nesse trabalho, revelando os instrumentos utilizados para a coleta de informações.

\section{PERCURSO METODOLÓGICO}

O sentimento do que somos depende das histórias que contamos e das que contamos de nós mesmos (...), em particular, das construções narrativas nas quais cada um de nós é, ao mesmo tempo, o autor, o narrador e o personagem principal. (LARROSA, 1999, p. 79)

A escolha do caminho metodológico de uma pesquisa é essencial para desvelar o objeto de estudo, uma vez que este nos ajuda a compreender os fenômenos existentes no campo pesquisado. Optamos por desenvolver esse trabalho na perspectiva (auto)biográfica por entender que a mesma me possibilitará a percepção do sujeito como centro da pesquisa, uma vez que a realizamos ouvindo narrativas de crianças pequenas. Cabe aqui destacar que essa percepção do outro é também resultado das nossas vivências formativas.

É bom esclarecer que a criança, como assevera Passegi (2011), é capaz de narrar, sendo protagonista de sua própria história. No entanto, as narrativas de crianças pequenas são bastante curtas e pontuais, mas revela muitas coisas. Assim sendo, buscamos nessa abordagem uma inspiração e não um desenvolvimento de entrevistas narrativas, pois não lograríamos êxito na coleta 
das informações. Há, no entanto, de se dizer que esse fato não impede o reconhecimento da criança enquanto sujeito que narra sob seu ponto de vista, fazendo aflorar as subjetividades que a compõe, produzindo discursos sobre o vivido e o experienciado.

A origem da pesquisa (auto) biográfica, enquanto método de investigação relaciona-se com mudanças que ocorreram no campo da Antropologia e da Sociologia por utilizarem pontos de vista superados em relação à análise da realidade. Assim, (Nóvoa 2007, p. 18), afirma que

[...] no campo educacional, sobretudo, a utilização contemporânea das abordagens (auto)biográficas é fruto da investigação das Ciências Sociais em relação ao tipo de saber produzido e da necessidade de uma renovação dos modos de conhecimento científico.

A metodologia da pesquisa (auto) biográfica sugere essa mudança na maneira de fazer ciência. Esse método surgiu por conta da insatisfação com as Ciências Sociais que tinha uma explicação do mundo e das relações de maneira ampla, diferente da (auto)biografia que trazia a ideia de que existem muitas histórias na história de uma pessoa, rompendo assim, com o paradigma positivista.

Portanto, o método (auto)biográfico possibilita a descoberta de si, a descoberta do seu percurso histórico, o revisitar memórias, sabendo que ela é algo que não se prende somente na subjetividade e que toda vivência, ainda que particular, encontra-se numa conjuntura histórica e cultural. Deste modo, as narrativas (auto)biográficas colocam o próprio sujeito, com sua forma de ver, e vivenciar o mundo e as coisas que o fazem objeto de análise da realidade, dando voz ao sujeito da investigação.

Trabalhar com narrativas não é somente angariar elementos, mas sim, fazer parte do processo de construção da memória a ser conduzida a partir da mediação do pesquisador. Portanto, o investigador, tem papel fundamental no processo de escuta das narrativas já que, "é, seguramente, a forma de máxima implicação entre quem entrevista e a pessoa entrevistada" (Moita, 1995, p. 272). Sendo assim, as narrativas (auto)biográficas consistem em fazer vir à tona, histórias de vida, biografias e (auto)biografias. Elas nos permitem, dependendo do modo como nos são contadas, universalizar as experiências nas trajetórias de nossos entrevistados.

Nesta perspectiva, o uso de narrativas (auto)biográficas como fonte de investigação, valida a criança, o adulto, o adolescente, enquanto sujeitos de direito, capazes de narrar a sua própria história e de pensar sobre elas. Para tanto, a criança tem uma forma característica de narrar sua vida, mostrando o mundo da forma como ela o vê, a partir de suas vivências e da sua imaginação. É 
preciso então incluí-las como sujeitos de direitos e não como objeto de pesquisa, para que suas práticas discursivas não sejam excluídas.

Um dos desafios da pesquisa (auto) biográfica com crianças é descobrir uma estratégia para ouvir o que elas têm a dizer sobre si mesmas, suas vivências, suas narrativas do cotidiano. É preciso assim, olhar a infância levando em consideração as singularidades da criança, entendendo, que ela é um ser capaz de pensar ao falar sobre suas experiências. Para Passeggi (2011),

A pesquisa (auto)biográfica se inscreve num movimento científico e cultural que impulsionou, nos anos 1980, o retorno do sujeito-ator-autor às pesquisas em Ciências Humanas e Sociais. Face ao declínio dos grandes paradigmas estruturalismo, marxismo, behaviorismo - a linguagem como prática social, o cotidiano como lócus da ação e o saber do senso comum, passam a ocupar um lugar central na tessitura de outros laços entre sujeito/objeto, indivíduo/ sociedade, determinismo/ emancipação, inconsciente/ consciência [...]. (PASSEGGI, 2011, P. 13).

Ao se realizar uma pesquisa com crianças, é preciso levar em consideração o empenho das mesmas para refletir sobre o que sentem ou o que desejam. Precisamos ouvir as histórias que elas têm para nos contar, porque é também pelos sentidos das crianças que conhecemos suas culturas, a sua história de vida e isso faz dessas narrativas o material mais apropriado para compreender a infância. Na visão de Dunn (1988) os estilos narrativos existentes na nossa cultura se iniciam nas primeiras interações entre o adulto e a criança, pois é inicialmente no cotidiano familiar que ela aprende a se relacionar e a construir suas histórias.

Contudo, compreender a interpretação da criança em suas narrativas, é um desafio muito grande, pois exige do pesquisador uma maior exatidão para que possa se aproximar da visão de mundo sem interferir na maneira de pensar da criança. Na pesquisa com crianças, é importante criar vínculos, conviver cotidianamente com elas, escutá-las para que haja uma cumplicidade entre as partes envolvidas, pois, como nos fala Graue e Walsh (2003),

[...] jamais vemos o mundo através dos olhos das crianças, elas têm percepções bastante particulares. Veremos sempre o mundo através de uma multiplicidade de camadas de experiências das crianças e nossas, de uma multiplicidade de camadas de teorias. (GRAUE e WALSH, 2003, p. 56)

A criança é dotada de possibilidades, ao mesmo tempo que é espectador, também é espetáculo, ela consegue retornar a si mesmo para externar o que sente, com a ajuda da linguagem em suas diversas formas. Ao narrar, a criança reflete sobre suas experiências, seja no cotidiano, na escola, na brincadeira, estendendo assim, suas formas de ver o mundo. Portanto, é imprescindível 
ouvir as crianças e corroborar com suas reflexões sobre o que fazem e o que pensam para que possam construir a sua identidade narrativa.

Assim, a criança narra para si e para o outro o que acontece, sendo a narrativa uma ferramenta de acomodação de suas experiências, servindo como meio de comunicação e de construção de sua identidade. A essa disposição do ser humano de olhar para si mesmo, de falar o que sente, Passeggi (2014) deu o nome de reflexividade (auto)biográfica, que através do ato de narrar, nos permite retomar as nossas próprias vivências para nós e para os outros. Já Ferreira (2008, p. 153) nos fala da ideia de reflexividade na visão do pesquisador, por meio do qual ele necessita perceber suas "práticas de investigação e o processo de produção do conhecimento". Portanto, é preciso, dentro da pesquisa em educação levar em consideração a produção do conhecimento com e sobre as crianças.

A pesquisa (auto)biográfica tem como grande desafio, descobrir métodos adequados para a coleta de informações, pois, ao se tratar de crianças, é preciso garantir a sua participação como sujeito social, tornando as suas narrativas um objeto de estudo valoroso, para que possam expressar suas vivências em diferentes ambientes que fazem parte do seu contexto. Nessa direção, a pesquisa com crianças demanda outro olhar:

Esse outro olhar que estamos nos propondo a construir exige a compreensão de que as crianças à sua moda compreendem o mundo que as cerca. Portanto, são sujeitos completos em si mesmos, que pensam se expressam criativamente e criticamente sobre o espaço institucional onde são educadas e cuidadas. São sujeitos conscientes de sua condição e situação e se expressam de múltiplas formas. (CERISARA, 2004, p.37).

Valorizar os dizeres das crianças e a sua percepção do ambiente escolar pode sugerir melhorias para o sistema educacional. A criança precisa ter um espaço para que ela fale sobre suas experiências, suas vivências na escola e assim, tenha um sentimento de pertencimento desse espaço.

Para Conti e Passeggi (2014, p. 153), a construção de um ambiente de faz de conta "propício ao desenvolvimento da dimensão narrativa" é indispensável para que a criança se sinta confortável para se expressar e relatar suas experiências construídas no seu cotidiano.

Interpretar as narrativas das crianças é desafiador, é preciso ter muito cuidado para se aproximar ao máximo das suas falas, deixando as preocupações teóricas de lado, para não por em risco o modo de pensar das crianças. Nesse sentido nos fala Bertaux (2010, p. 18), "existe narrativa de vida desde que haja descrição sob forma narrativa de um fragmento da experiência vivida". 
Para tanto, as operações que fazem parte da transmissão da oralidade para a escrita, fazem do pesquisador um intermediário entre o leitor e o narrador. Os cuidados éticos precisam envolver todo o percurso da pesquisa, da construção da coleta de dados, até o método de análise. Neste sentido, foram utilizadas as rodas de conversa que por ser um meio de participação de todos os envolvidos, aborda uma determinada temática onde possam dialogar, se expressar e escutar seus pares e a si mesmo. Ao falar o sujeito divide, com os outros, suas experiências e aprende a argumentar, instigando o grupo a novos diálogos, construindo um espaço de aprendizado e de troca.

Desta maneira, é preciso garantir que na roda de conversa todos falem e sejam ouvidos para que se sintam parte integrante do processo e para que tenham suas histórias de vida reveladas e respeitadas. Durante a pesquisa foram feitas três rodas de conversa com as crianças no coletivo. Cada rodinha foi realizada em um espaço diferente, com o objetivo de entender o que as crianças traziam em suas falas e perceber qual a relação das mesmas com cada espaço. A duração de cada roda de conversa variou de acordo com as reações e a disponibilidade de cada crianças. As rodinhas foram divididas por temas; os espaços e as brincadeiras e a visão da escola. Foram momentos descontraídos, feitos na brinquedoteca, na sala de aula e no pátio, para que as crianças pudessem se sentir à vontade. A cada rodinha realizada as crianças fizeram desenhos para representar os espaços da escola, o que contribuiu para a análise dos dados da pesquisa, pois, desenhar é uma forma de a criança lidar com a realidade que a cerca, representando situações do seu dia a dia.

A escolha de rodas de conversa como dispositivo para realização desta pesquisa é conveniente por ser um momento em que a criança tem a chance de expressar seus pensamentos de maneira informal, de modo que nas rodas há a possibilidade da criança realizar a construção de um momento de fala e de escuta, interagindo com seus pares. A roda é um ambiente rico e estimulador de conhecimento, pelo fato das crianças praticarem sua oralidade, apresentando seus desejos e questionamentos. Nesse sentido, o Referencial Curricular Nacional para Educação Infantil (Brasil, 1998, p. 127) diz que "durante a roda de conversa existe uma constante troca de ideias que resultará no aumento da capacidade comunicativa como a fala, a exposição de ideias, dúvidas e descobertas". Além das rodas, conversamos individualmente com cada criança, a fim de perceber as regularidades do que havia trazido nas rodas. Foi o momento individual de perceber o que cada uma acrescentaria para além do que já tinha narrado com os colegas.

Assim, este trabalho se insere numa abordagem qualitativa que é revelada por aquilo que não pode ser medido, pois a realidade e o sujeito são elementos inseparáveis. Portanto, quando se 
fala do sujeito, devem ser levados em consideração seus traços pessoais e suas características. Essas mudanças não podem ser manifestadas em números quantificáveis.

\section{CONCEPÇÕES DE AMBIENTE E ESPAÇO/TEMPO}

Nos últimos anos, tem crescido o reconhecimento da importância dos elementos que compõem os ambientes sobre o desenvolvimento das crianças. O formato como o espaço físico está organizado na Educação Infantil intervém no desenvolvimento das crianças, já que a escola é o lugar onde elas passam grande parte do seu tempo. Assim, as escolas precisam estar preparadas para recebê-las, proporcionando a elas momentos de interação com ambientes ricos e estimuladores.

Se voltarmos ao passado, podemos constatar, através de referências teóricas que os espaços no campo educacional interferiam no disciplinamento e no controle dos movimentos corporais das crianças, que eram controladas, não tendo permissão para interagir com os colegas. As cadeiras eram enfileiradas para que os professores tivessem um maior controle sobre a turma, se tornando o centro das atenções. Grande parte das escolas no Brasil, ainda oferece um espaço que determina a disciplina, mantendo as crianças imóveis.

Assim, durante muito tempo, o espaço foi considerado um elemento neutro, qualquer lugar poderia abrigar as crianças. Só, a partir do lançamento do "Referencial Curricular Nacional para a Educação Infantil" - RCNEI (1998) é que o ambiente físico passou a ser visto de maneira a atender às necessidades e características das crianças.

A organização deste espaço deve ser pensada tendo como princípio oferecer um lugar acolhedor e prazeroso para a criança, por ser, em grande parte responsável pela qualidade das comunicações, das relações internas da escola e da qualidade do projeto educativo. Diferentes ambientes se constituem dentro de um espaço. De acordo com Horn (2004):

É no espaço físico que a criança consegue estabelecer relações entre o mundo e as pessoas, transformando-o em um pano de fundo no qual se inserem emoções [...] nessa dimensão o espaço é entendido como algo conjugado ao ambiente e viseversa. Todavia é importante esclarecer que essa relação não se constitui de forma linear. Assim sendo, em um mesmo espaço podemos ter ambientes diferentes, pois a semelhança entre eles não significa que sejam iguais. Eles se definem com a relação que as pessoas constroem entre elas e o espaço organizado. (HORN 2004, p.28)

Admitindo que a criança é profundamente marcada pelo meio social em que se desenvolve, que também deixa suas próprias marcas neste meio e que o desenvolvimento humano ocorre na e 
através da interação social, sendo que nessa interação a criança constrói seu conhecimento e a si mesmo enquanto sujeito, o espaço infantil deve dar prioridade em expandir a história da criança para o seu contexto e através disto promover a troca de saberes entre as crianças. Segundo o Referencial Curricular Nacional da Educação Infantil (1998, vol. 1, p. 21-22):

As crianças constroem o conhecimento a partir das interações que estabelecem com as outras pessoas e com o meio em que vivem. O conhecimento não se constitui em cópia da realidade, mas sim, fruto de um intenso trabalho de criação, significação e ressignificação. (RCNEI, 1998, p. 21-22)

As interações que acontecem dentro dos espaços escolares têm uma grande influência na aprendizagem da criança. A atual legislação educacional brasileira é composta por um conjunto de documentos que norteiam no sentido de se determinarem critérios de qualidade para a infraestrutura das escolas. A Lei de Diretrizes e Bases para a Educação Nacional 9.394/96 diz que os recursos públicos voltados para a educação precisam ser aplicados na manutenção e na ampliação do ensino público no que diz respeito a "aquisição, manutenção, construção e conservação de instalações e equipamentos necessários ao ensino" (alínea IV do artigo 70).

O ambiente físico, para o RCNEI, deve ser disposto de forma a suprir as necessidades e particularidades dos grupos de crianças, priorizando a cultura da infância e os diferentes projetos e atividades que serão desenvolvidos com seus professores. A qualidade da relação criança-criança, criança-adulto, criança com os objetos, brinquedos e móveis presentes no ambiente dependem da forma como são organizados, podendo se transformar em "poderosos instrumentos de aprendizagem" e em um dos "indicadores importantes para a definição de práticas educativas de qualidade" (p.146).

Portanto, ao se refletir sobre o modo como os espaços da educação infantil estão organizados, é preciso conhecer esses espaços, bem como a maneira que as crianças interagem com eles. Os termos espaço e ambiente, apesar de estarem intimamente ligados, têm significados e entendimentos diferentes, sendo o espaço os locais onde as atividades são realizadas, contendo móveis, objetos, material didático, decoração. O ambiente é um conjunto do espaço físico com as relações que se formam abarcando os afetos, a convivência, as relações com o outro.

O espaço não é só um pano de fundo para as aprendizagens, ele intervém diretamente no aprendizado das crianças sendo interlocutor por desafiar as crianças à exploração, ao movimento, à produção de linguagem. Segundo os Parâmetros Nacionais de Qualidade para a Educação Infantil, o espaço físico para crianças de 1 a 6 anos deve ser visto como um suporte que possibilita e contribui 
para a vivência e a expressão das culturas infantis - jogos, brincadeiras, músicas, histórias que expressam a especificidade do olhar infantil.

O espaço na educação infantil é como um terceiro educador já que a criança aprende com o adulto, aprende com outras crianças e também aprende com o próprio espaço. Se o espaço convida a criança para uma ação, na experiência dessa ação ele está aprendendo sem necessariamente precisar da presença de um adulto. A forma como o espaço está organizado muitas vezes é a grande intervenção do adulto.

\subsection{O PÁTIO E A HORA DA BRINCADEIRA}

O pátio escolar é um lugar essencial para o desenvolvimento infantil. Acreditamos que a escola tem papel fundamental para a socialização e que ela complementa o papel iniciado pelo ambiente familiar. É no pátio que acontece a maior interação por ser o local de encontro de todos da escola. Neste sentido, as crianças ${ }^{3}$, sujeitos desta pesquisa, declararam o pátio como sendo o lugar preferido por ser um ambiente onde eles se sentem livres, com espaço para brincarem da forma que desejam. O pátio da escola tem um bom tamanho, é coberto e contém um pequeno parquinho. No momento do intervalo cada professora leva sua turma o e as atividades realizadas podem ser livres ou dirigidas. Na roda de conversa as crianças relataram sobre o pátio:

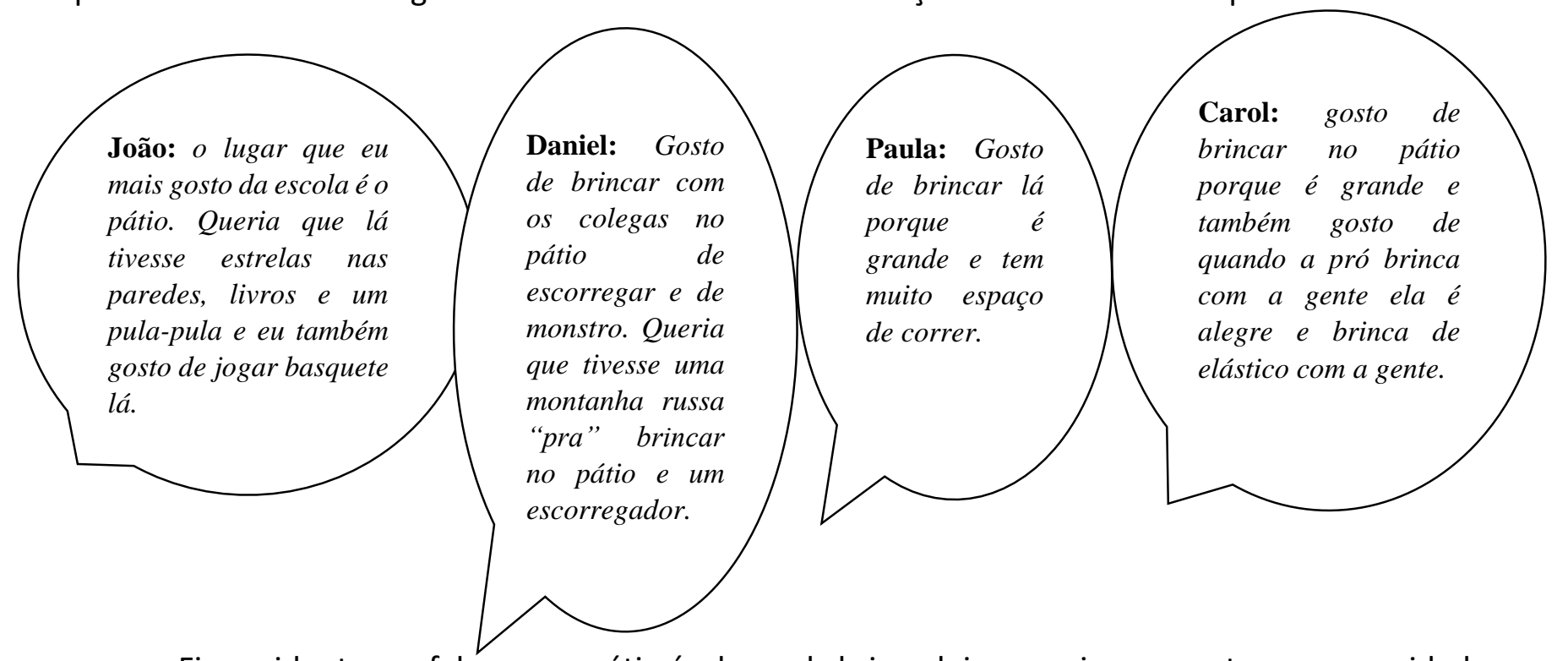

Fica evidente nas falas que o pátio é o lugar da brincadeira, as crianças sentem a necessidade de um espaço amplo para que possam realizar vários tipos de brincadeira, correr, pular, jogar bola. A fala de Paula, quando diz que gosta do pátio porque é grande e tem espaço para correr mostra o

\footnotetext{
${ }^{3}$ Para preservar a identidade das crianças, os nomes aqui são fictícios, escolhidos por elas mesmas.
} 
desejo de liberdade. Já João, aponta como gostaria que esse espaço fosse organizado, sentido falta de um lugar mais colorido e com mais brinquedos.

Ao falar da brincadeira é interessante destacar a importância do brinquedo para as crianças, pois eles são um convite para o ato de brincar. De acordo com Cunha (1994), os brinquedos também são responsáveis pela socialização das crianças já que, é a partir deles que elas assimilam valores e crenças.

A primeira roda de conversa revela que apesar de gostarem da forma como o pátio está organizado, as crianças recomendam mudanças. A partir de suas falas fica notória a necessidade de torná-lo mais colorido e divertido. Cruz (2008) acrescenta que ouvir as vozes das crianças nos fornece elementos para que possamos modificar os espaços escolares e transformá-los em locais para o educar e o brincar respeitando suas vontades.

\subsection{PERCEPÇÕES DA SALA DE AULA}

Durante a realização da segunda roda de conversa, falamos sobre a sala de aula. Nos momentos de observação vimos que é uma sala climatizada e com um bom tamanho, possui mesas e cadeiras adequadas para a idade, prateleiras onde são guardados os materiais coletivos, numa altura em que as crianças possam acessar, o que de certa maneira promove o desenvolvimento da autonomia das crianças, já que podem pegar os materiais e objetos sem a ajuda de um adulto, realizando suas próprias escolhas. Possui também um expositor de livros, alguns baldes com brinquedos e um espelho. Nas paredes estavam expostos alguns cartazes feitos pelos alunos além de tabela numérica, calendário e quadro de aniversariantes.

Chamou nossa atenção a forma como as mesas estavam dispostas na sala sempre na mesma posição e com os nomes dos alunos que possuem lugares fixos escolhidos pela professora por entender que as crianças que conversam muito têm que ficar separadas e que isso facilita a rotina da sala. O modo como os materiais e a sala de aula estão organizados motiva as crianças a interagirem promovendo, assim, um protagonismo infantil nas ações desenvolvidas neste espaço. Ao instigá-las revelaram que gostam da sala de aula, dos brinquedos e das atividades propostas pela professora. Veem a sala como um espaço em que podem brincar e que como dito por João se divertem com a professora que para eles é muito carinhosa, mas também fica brava em alguns momentos. Gostam quando a professora conta histórias e participa das brincadeiras propostas por 
eles. Mas, apesar de todas as crianças terem dito gostar da sala de aula, sugeriram algumas mudanças:
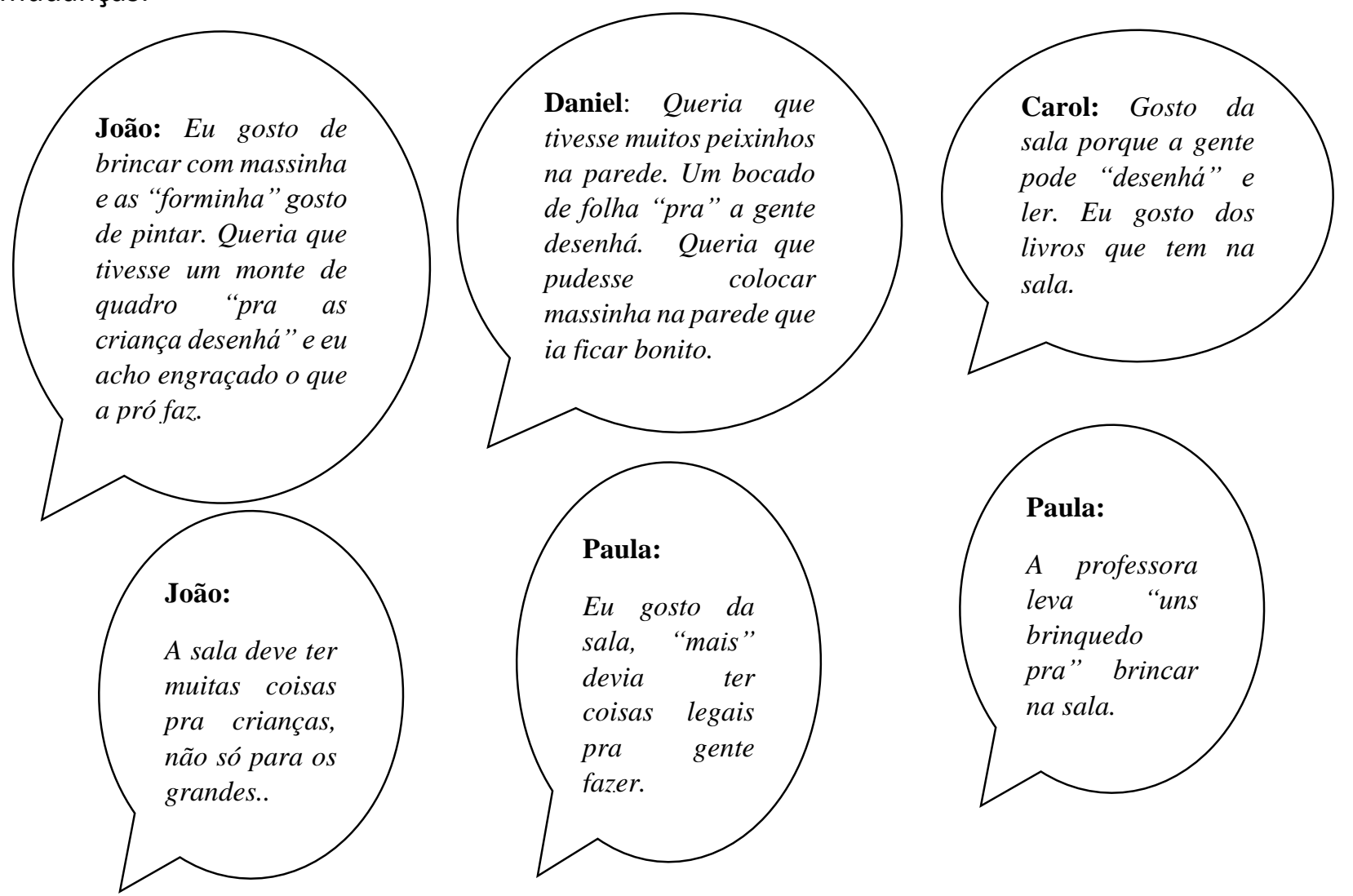

As narrativas das crianças revelam o desejo de uma sala de aula mais colorida e lúdica e que elas possam se expressar de várias formas com desenhos, pinturas, esculturas e que as suas produções possam estar expostas na sala, fazendo com elas percebam que fazem parte desse espaço. Desta forma, no momento de ouvir as crianças é necessário também observar como elas se comportam na sala de aula, quais são suas brincadeiras e brinquedos preferidos, para então ampliar o conhecimento e a percepção a partir do que as crianças desejam para o espaço escolar.

Voltando o olhar para os materiais escolhidos para a sala, é importante considerar alguns pontos. Não é preciso fornecer uma quantidade muito grande, mas que seja suficiente para a quantidade de crianças da turma. Estes materiais devem ser atraentes para as crianças, fornecendo desafios constantes para que favoreçam as construções individuais e coletivas. Um conceito importante é depois de algum tempo, trocar alguns materiais de sala, permitindo, assim, que todas as crianças da escola tenham acesso a esses materiais, pensando sempre que precisam ser adequados à faixa etária.

Deste modo, é importante considerar que o uso de materiais não estruturados como tecidos, caixas, tampinhas, pneus, cordas, elementos da natureza, dentre outros, consente a criança a modificar os objetos e os espaços tendo assim a possibilidade de vivenciar um experimento novo e 
enriquecedor a cada brincadeira. Diferente dos brinquedos convencionais, esses materiais instigamnas a criar, a inventar e a criança vivencia um ambiente que seduz a buscar, a pesquisar, a pensar sobre o objeto e as probabilidades de atuação sobre eles.

Assim, um olhar atento para o espaço escolar pode enxergar muito das visões das pessoas que o organizaram. A maneira como os materiais estão dispostos na sala de aula pode desafiar o aluno ou não. Em relação a isto, Horn (2004) diz:

(...) o espaço nunca é neutro, pois carrega sua configuração, como território e lugar, signos e símbolos que o habitam. Na realidade, o espaço é rico em significados, podendo ser "lido" em suas representações, mostrando a cultura em que está inserido através de ritos sociais, de colação e de uso de objetos, de relações interpessoais etc. Por meio da leitura 'das paredes e da organização dos espaços' das salas de aula de instituições de Educação Infantil, é possível depreender que concepção de criança e de educação o educador tem. (Horn, 2004, p. 37)

O professor precisa refletir muito sobre a sua prática e poder repensar o espaço que está sendo oferecido para a sua turma. Analisar se os objetivos pedagógicos estão sendo alcançados, precisa fazer parte do seu dia a dia para que possam perceber se é necessária uma reorganização desses materiais.

\subsection{BRINQUEDOTECA}

O brincar é uma atividade constante na vida de toda criança, é algo natural e muito importante para o seu desenvolvimento. Para as crianças participantes desta pesquisa a brincadeira faz parte do dia a dia da escola e está presente em todos os espaços. Elas apresentam a brinquedoteca como um lugar pequeno, o que ficou claro na fala de Paula. Para ela o espaço não é suficiente para acolher as crianças da turma, ficando desconfortável o momento do filme. Já Daniel gosta do espaço por conter muitos brinquedos. A brincadeira revela a forma como a criança pensa, ordena e organiza o mundo, é um ato onde ela pode se expressar de modo simbólico, suas fantasias, seus medos e os conhecimentos que vão construído ao longo de suas experiências. Para Piaget (1978), a criança, quando brinca, assimila o mundo do seu jeito, sem compromisso com a realidade.

Para tanto é importante destacar que a brinquedoteca é muito pequena e é utilizada também como sala de vídeo. Contém televisão, aparelho de DVD e tatame. Nas paredes há algumas prateleiras com uma boa quantidade de livros que ficam ao alcance das crianças. Apresenta também algumas prateleiras com alguns jogos aos quais as crianças não conseguem alcançar. No chão, 
alguns baldes de brinquedos, móveis e eletrodomésticos feitos de papelão que são pouco utilizados pelos alunos. Não possui espaço suficiente para que as crianças possam se movimentar livremente.

Assim, sobre a brinquedoteca as crianças disseram:

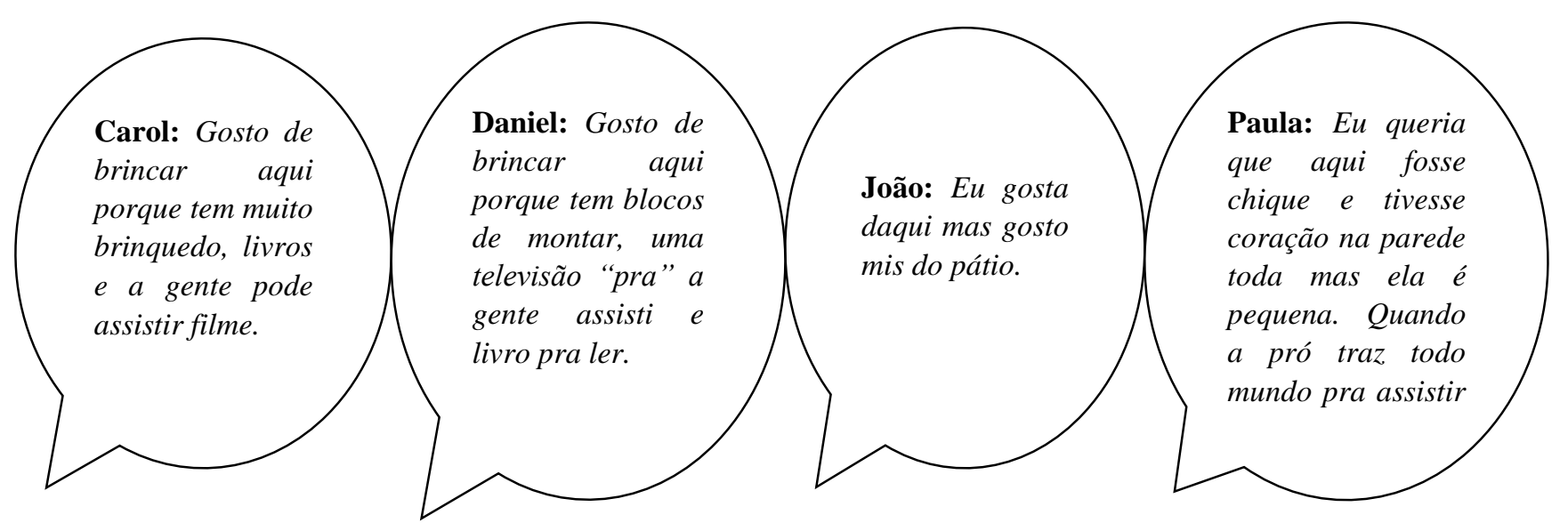

A brinquedoteca é um dos espaços essenciais para o brincar, já que ela proporciona por meio de atividades lúdicas, um ambiente para a construção do ser social, histórico, lugar onde as crianças apresentam suas ideias, expressam sua cultura interagindo com o espaço e com os pares. Portanto, a brinquedoteca:

É um espaço preparado para estimular a criança a brincar, possibilitando o acesso a uma grande variedade de brinquedos, dentro de um ambiente especialmente lúdico. É um lugar onde tudo convida a explorar, a sentir, a experimentar. Quando uma criança entra na brinquedoteca deve ser tocada pela expressividade da decoração, porque a alegria, o afeto e a magia devem ser palpáveis. Se a atmosfera não for encantadora não será uma brinquedoteca. Uma sala cheia de estantes com brinquedos pode ser fria, como são algumas bibliotecas. Sendo um ambiente para estimular a criatividade, deve ser preparado de forma criativa, com espaços que incentivem a brincadeira do "faz de conta", a dramatização, a construção, a solução de problemas, a sociabilização e a vontade de inventar: um camarim com fantasia e maquilagem, os bichinhos, jogos de montar, local para os quebra-cabeças e os jogos (CUNHA, 2010, p. 36-37).

É preciso garantir que toda brinquedoteca seja um lugar acolhedor e aconchegante para que possa instigar a criança a brincar. Para isso, é fundamental a presença de profissionais capacitados para organizar a brinquedoteca montando um ambiente divertido e iluminado, com jogos adequados, brinquedos, arejada e com diferentes espaços temáticos e significativos para as crianças. Sendo a brincadeira essencial para a criança, uma das atividades mais importantes realizadas na Educação Infantil, conforme o RCNEI (1998), a organização do espaço deve ser feita 
em parceria com a criança que brinca, pois, no arranjo dos brinquedos e espaços, a criança transmiti a sua personalidade, seus desejos e sonhos e constrói sua representação de mundo.

As instituições de Educação Infantil são espaços que promovem o desenvolvimento das crianças, pois, além de oferecer cuidados físicos, ela também cria condições para o seu desenvolvimento físico, cognitivo, simbólico, social e emocional. As crianças, sujeitos desta pesquisa, percebem a escola como sendo um lugar cheio de possibilidades para que elas possam se expressar das mais variadas formas. Para elas os espaços escolares precisam de cor, de brilho, precisam ter a cara, o gosto, os desejos das crianças expostos por todos os ambientes para que elas possam se sentir pertencentes daquele lugar.

Diante do exposto, entende-se a necessidade de momentos de diálogo na sala, ouvir o que as crianças têm a dizer para que possa ser realizado um trabalho na perspectiva da interação e da autonomia onde o educando possa se expressar sentido à prática educativa. Proporcionar esse diálogo é aceitar a sua livre expressão possibilitando intervenções nos contextos vividos. Ao se pensar na organização do espaço na Educação Infantil é fundamental pensar nas crianças, em como elas aprendem e como utilizam esses espaços.

Pelas observações e narrativas das crianças, percebemos que a organização dos espaços assim como a estrutura física que não foi construída pensando em uma escola de Educação Infantil, mas pensada inicialmente para outro propósito. Os espaços não contribuem de maneira significativa com o desenvolvimento das crianças que se sentem limitadas com relação ao tamanho dos espaços e por não se sentirem desafiadas a explorá-los. Desta forma, os espaços ainda não têm contemplado todos os desafios para a aprendizagem das crianças por não serem desafiadores e atrativos já que prazer, estética e brincadeiras são essenciais para qualquer ato de aprendizagem e construção do conhecimento.

Para tanto, o ambiente tem que se tornar uma superfície refletora em que os protagonistas da experiência de aprendizagem consigam ver os traços de sua atuação e isso os torna capazes de falar sobre como estão aprendendo. É necessário oferecer às crianças espaços e objetos ideais que contribuam com suas aprendizagens, tendo em mente os espaços nos quais as crianças constroem suas identidades e suas histórias pessoais tanto reais como imaginárias. A forma como organizamos os espaços mostra como vemos as crianças. O que pensamos sobre elas torna-se um fator determinante na definição de sua identidade, de seus direitos e dos contextos educacionais apresentados a elas. É preciso enxergar a criança como ser competente e crítico capaz de construir seus próprios símbolos e códigos ao mesmo tempo em que aprende a decodificar os símbolos e 
códigos já estabelecidos pois os caminhos e processos de aprendizagem das crianças passam pela relação com o contexto espacial e temporal que deve ser um ambiente ideal para o seu desenvolvimento.

\section{CONSIDERAÇÕES}

O estudo evidenciou como as crianças revelaram seu interesse por um espaço esteticamente bonito e que lhes permita realizar jogos, brincadeiras e atividades como desenhar, pintar e ler. Mas, também percebem os aspectos que precisam ser melhorados no espaço escolar. Elas apontam que seus espaços preferidos são o pátio, a sala de aula e a brinquedoteca onde ocorre a realização destas atividades. O espaço escolar é socialmente construído, portanto a criança enquanto ser social faz parte desse processo.

Essa pesquisa mostrou que a criança além de representar visualmente o espaço físico, traz nas suas falas as relações que acontecem ali. Falam sobre a aparência do ambiente, de objetos e brinquedos que gostariam que existisse na escola, da rotina escolar, das interações e trazendo lembranças ao arquitetar o espaço. A análise das narrativas das crianças consentiu perceber que a maioria delas aprecia o espaço escolar e tem opiniões sobre o que é necessário fazer para melhorálo. Reconhecem também que esse espaço permite a realização de várias brincadeiras, jogos e muito aprendizado, mas determina, mesmo que de forma sutil, outros elementos que faltam no espaço.

Nas relações construídas com seus pares e com o meio, a criança desenvolve a linguagem, condição essencial para o desenvolvimento humano. Assim, a realização das rodas de conversas para ouvir o que pensam e desejam as crianças sobre o espaço da escola legitimou o estudo aqui realizado. Para tanto é preciso refletir e discutir sobre o espaço educativo adequado, sendo acolhedor, sociável, e que contribua à criança na sua rotina diária interligando conhecimentos de família, escola e sociedade. Dessa forma, concordamos com Horn $(2004$, p.16) quando nos diz que “o espaço não é algo dado, natural, mas sim construído. Pode-se dizer que o espaço é uma construção social que tem estreita relação com as atividades desempenhadas por pessoas nas instituições."

O espaço deve ser desafiador, estimulador, aconchegante, que desperte o interesse, participação, proporcionando o brincar, criar, imaginar, construir suas brincadeiras; "viajar" no mundo das fantasias, do significado, permitindo a produção de conhecimento durante a brincadeira, para que a criança supere seus limites e construa suas potencialidades, desenvolvendo 
diferentes áreas de conhecimento de forma cognitiva e motora. Neste sentido, entende-se que o presente estudo poderá servir de subsídio para refletir a organização dos espaços das instituições de educação infantil do município de Irecê-BA e contribuir para possíveis adequações ou reforçar os aspectos positivos da sua organização.

O método (auto) biográfico foi significativo para que se pudesse ouvir as narrativas das crianças que são pouco ouvidas ou que têm um pequeno espaço para expor-se. Com isso, as narrativas foram se revelando a cada rodinha de conversa, as particularidades de cada criança em relação aos espaços escolares. Enfim, embora o espaço e a organização do ambiente escolar sejam pouco pensados, os discursos das crianças sugerem a necessidade de uma maior discussão e inquietação sobre a importância dessa organização para que possa atende-las, levando em consideração suas opiniões e representações.

\section{REFERÊNCIAS}

ARIÈS, Philippe. História social da criança e da família. Rio de janeiro: Zahar, 1981.

BERTAUX, D. Narrativas de vida: a pesquisa e seus métodos (Z. A. C. Cavalcante \& D. M. G. Lavallée, Trad.). Natal: EDUFRN. 2010.

BRASIL, Lei de Diretrizes e Bases da Educação Nacional. Lei n 9394, de 20 de dezembro de 1996.

BRASIL. Constituição (1988). Constituição da República Federativa do Brasil. Brasília, DF: Senado, 1988.

BRASIL. Ministério da Educação e do Desporto. Secretaria de Educação Fundamental. vol. 3. Referencial curricular nacional para educação infantil. Brasília: MEC/SEF, 1998, (v.2.3).

CERISARA, Ana Beatriz. Em busca do ponto de vista das crianças nas pesquisas educacionais: primeiras aproximações. In SARMENTO, Manuel Jacinto. CERISARA, Ana Beatriz. Crianças e miúdos: perspectivas sociopedagógicas da infância e educação. Lisboa: Asa editores, 2004.

CRUZ, S.H.V.(Org.). A criança fala: a escuta de crianças em pesquisas. São Paulo: Cortez, 2008 CUNHA, Nylse Helena Silva. Brinquedoteca: um mergulho no brincar. 2. ed. São Paulo: Maltese, 1994.

DUNN J. Sibiling Influences on Childhood development. J Child Psychol Psychiat; v. 29(2), pp.119127, 1988.

FERREIRA, M. M. Martinho. "Branco demasiado" ou... Reflexões epistemológicas, metodológicas e éticas acerca da pesquisa com crianças. In: SARMENTO, M.; GOUVÊA, M. C. S. de (Orgs.). Estudos da infância: educação e práticas sociais. Petrópolis: Vozes, 2008, p. 143-162. 
FREIRE, P. Pedagogia do Oprimido, 43 a ed. Rio de Janeiro, Paz e Terra, 2005.

GRAUE, Elisabeth; WALSH, Daniel. Investigação etnográfica com crianças: teorias, métodos e ética. Lisboa: Fundação Calouste Gulbenkian, 2003.

HORN, M. G. S. Sabores, cores, sons, aromas: a organização dos espaços na educação infantil. Porto Alegre: Artmed, 2004.

HORN, M. G. S. Educação infantil: para que te quero? Porto Alegre: Artmed, 2011.

LARROSA, Jorge. Pedagogia profana - danças piruetas e mascaradas. 2 ed. Belo Horizonte: Autêntica, 1999.

MOITA, M.C. Percursos de formação e de Trans-Formação. In NÓVOA, A. Vidas de professores. Porto: Porto Editora, 1995.

NÓVOA, A. (Org.). Os professores e as histórias da sua vida. In.: NÓVOA, Antonio. Vidas de professores. 2 ${ }^{\text {a }}$ ed. Porto: Porto Editora, 2007.

PASSEGGI, Maria da Conceição. A experiência em formação. Revista Educação, Porto Alegre, v. 34, n. 2, p. 147-156, maio/ago. 2011.

PASSEGGI. Maria da Conceição. Nada para a criança, sem a criança: o reconhecimento de sua palavra para a pesquisa (auto) biográfica. In: Mignot, A.C., Sampaio, C.S. \& Passeggi, M. C. Infância, aprendizagem e exercício da escrita. (PP. 133-148). Curitiba, PR: CRV. 2014.

PIAGET, Jean. A formação do símbolo na criança. Rio de Janeiro, Zahar, 1978.

VYGOTSKY, L.S. Conscience, inconscient, émotions. Paris: La Dispute, 2003.

\section{SOBRE OS AUTORES}

\section{Fabrício Oliveira da Silva}

Pós-doutorando e Doutor em Educação e Contemporaneidade -PPGEduC da Universidade do Estado da Bahia - UNEB. Professor Adjunto do Departamento de Educação da Universidade Estadual de Feira de Santana UEFS. Professor permanente do Programa de Pós-Graduação em Educação PPGE da UEFS. Coordenador do Núcleo de Estudos e Pesquisas sobre Pedagogia Universitária - NEPPU/UEFS. Více-lider do Grupo de Pesquisa Docência, Narrativa e Diversidade na Educação Básica - DIVERSO. E-mail: fosilva@uefs.br ORCID https://orcid.org/0000-0002-7962-7222

\section{Michele Rodrigues Marques}

Especialista em Educação Infantil pela Universidade do Estado da Bahia - UNEB. Professora de Educação Infantil da Rede Municipal de Educação de Morro do Chapéu-Ba. E-mail: mi r marques@hotmail.com Orcid: https://orcid.org/0000-0001-8814-5623 